\title{
Post-Thaw Evaluation of Cryopreserved Boer Crossbred Buck Semen Extended in TEYG (Universal) Extender and its Fertility Rate
}

\author{
S. Manivannan*, M. Selvaraju, R. Ezakial Napolean and P.S.L. Sesh \\ Department of Veterinary Gynaecology and Obstetrics, Veterinary College and Research \\ Institute, Namakkal, Tamil Nadu, India \\ *Corresponding author
}

\author{
A B S T R A C T
}

\begin{tabular}{|l|}
\hline Ke y w or d s \\
Post-Thaw \\
evaluation, TEYG, \\
Fertility rate.
\end{tabular}

\section{Introduction}

The Boer breed of goat is well known for its good meat production ability and high prolificacy and butits adaptability in a tropical and sub-tropical region is difficult (Ramsay et al., 1987). Hence the development of Boer crossbred is essential to utilize its germplasm in order to maximize the profit to the goat farmers. Artificial insemination (AI) has become an inevitable tool in the breeding management of most of the domestic animals. It has been successfully implemented in breeding of bovines but is still lacking in goats for its efficiency. The commercial use of cryopreserved semen has not been popular in caprine reproduction. Tris- egg- yolk based extenders have been widely used for freezing of buck semen (Moussa et al., 2002).

Sperm motility, in general and characteristics of sperm motion in particular could be some of the indicators of the quality of spermatozoa. Commonly, by evaluating the proportion of progressive motile percent at different stages, the quality of semen is monitored. However, evaluation of characteristics of sperm motion may provide valuable information on why certain samples despite containing good proportion of progressive motile spermatozoa pre freezing poorly freezable. Conventional methods of 
measurement of sperm kinematic characters is cumbersome, time consuming and subjective. To get over these difficulties Computer assisted semen analysis (CASA) is the equipment of choice to provide precise and accurate information on sperm motion characteristics. Therefore, a study was undertaken to analyze the changes in motility characteristics of Boer cross spermatozoa during after cryopreservation by Computer Assisted Semen Analysis (CASA) technique and its fertility rate.

In the last decades, oestrus synchronization together with AI is extensively applied in the reproductive management of goat to propagate the superior germplasm (Amle et al., 2017). In recent years, real-time ultrasonography has been used more frequently for pregnancy diagnosis in small ruminants (Hesselink and Taverene, 2017). At this juncture, a study was conducted to assess the post thaw sperm kinematic character by CASA and their efficacy on fertility rate of Boer crossbred buck semen.

\section{Materials and Methods}

Two Boer crossbred bucks aged between 41/2 and 5 years which are maintained at Frozen Semen Bank, Department of Veterinary Gynaecology and Obstetrics, Veterinary College and Research Institute, Namakkal were utilized for this study. The semen was collected from two adult Boer crossbred bucks. The semen was collected twice in a week and each time two ejaculates per buck was collected. The semen donor was allowed to mount on the dummy. Two false mounts were given before semen collection during every time. On third mount, the penis was directed in to AV and the semen was collected in a collection cup. The collected ejaculates were immediately transferred to semen processing laboratory and kept at $34^{\circ} \mathrm{C}$ water bath. The semen collected from the two bucks were pooled in to a sterile glass tubes and immediately subjected to analysis and immediately subjected to further processing and cryopreservation and finally stored in liquid nitrogen container. This semen straws were subjected evaluation by CASA at various storage period.

\section{Computer Assisted Semen Analyzer (CASA)}

In this study CASA was employed to study the kinematic character of Boer crossbred buck semen extended in TRIS universal extender. The CASA version used in this study was CASA: IVOS version No.14 was used to analyze sperm kinematic characteristics. The CASA settings were fixed with slight modification as described by Sundaraman et al., (2008).

A two $\mu$ l of neat pooled semen sample was diluted with $400 \mu \mathrm{l}$ of Tris solution. After dilution, two $\mu$ l of sample was loaded in one chamber of pre warmed Leja slide and kept in microscopic stage of CASA. Four fields were scanned automatically and sperm motility characteristics were determined with a 10Xobjective at $37^{\circ} \mathrm{C}$. The sperm kinematic characteristics viz., motility (per cent), progressive motility (per cent), VAP (Average Path Velocity, $\mu \mathrm{m} / \mathrm{sec}$ ), VSL (Straight Line Velocity, $\mu \mathrm{m} / \mathrm{sec}$ ), VCL (Curvi Linear Velocity, $\mu \mathrm{m} / \mathrm{sec}$ ), ALH (Amplitude of Lateral Head displacement, $\mu \mathrm{m}), \quad$ LIN (Linearity Index; LIN $=\{$ VSL/VCL $\}$ X 100) and the sperm the concentration were measured by using CASA.

\section{Post thaw semen analysis by CASA}

Frozen straws were taken from the storage container and placed into a water bath maintained at $37{ }^{\circ} \mathrm{C}$ for 30 seconds. After wiping the straws, the laboratory seal of semen straw was cut and the semen was 
poured into a sterile test tube.A $2 \mu$ of post thaw semen sample was diluted with $200 \mu \mathrm{l}$ of Tris / NS. After dilution, two $\mu$ l of sample was loaded in one chamber of pre warmed Leja slide and placed in microscopic stage of CASA. Four fields were scanned automatically and sperm motility characteristics were determined with a $10 \mathrm{X}$ objective at $37^{\circ} \mathrm{C}$. The motility characteristics were analyzed for frozen thawed semen as done for fresh semen samples as explained earlier.

\section{Estrus synchronization and evaluation of fertility rate}

Ten non pregnant pluriparous does were selected in villages in and around Namakkal. The selected does were subjected to estrus synchronization using intra vaginal sponge + $\mathrm{PGF}_{2} \alpha+\mathrm{eCG}$ protocol as explained by Baldassarre and Karatzas (2004).

The selected does were inserted with intravaginal sponges containing $0.35 \mathrm{mg}$ of synthetic progesterone on day 0 and kept insitu for 11 days. One day before sponge withdrawal (day10) 250 $\mu$ g of $\mathrm{PGF}_{2} \alpha$ and on the day of sponge removal (day11) $200 \mathrm{IU}$ of equine chorionic gonadotropin were given intramuscularly. The synchronized does were inseminated at fixed time using the frozen semen straws prepared in universal extenders and the conception rate was analyzed.

\section{Artificial insemination and pregnancy diagnosis}

After 48 hours of eCG injection, the confirmation of estrus was done by examining the changes in vulva, vaginal mucous membrane, mucus discharge and by visualizing external cervical os of the does with the help of speculum along with borescope. With the help of borescope the external os was clearly visualized for the changes during estrum. All selected ten does were artificially inseminated with previously prepared semen straws by using borescope which helped in proper deposition of semen at the mid cervix. Pregnancy diagnosis was carried out by ultrasonography after $45^{\text {th }}$ day of AI. The collected was analyzed statistically. Statistical evaluations were carried out using the statistical package for social studies software (SPSS version 20).

\section{Results and Discussion}

Effect of TRIS semen extenders on sperm kinematic characteristics evaluated by CASA of post freeze stage buck semen at different storage period is depicted in Table. 1. The majority of the post-thaw sperm motility parameters such as Sperm motility, Progressive motility, Average path velocity, Straight line velocity, Curvilinear velocity, Amplitude of lateral head displacement, Beat cross frequency and Linearity index evaluated by CASA were significantly higher at 24 hours and decrease progressively as the duration storage period increases. On evaluation of effect of freezing, it was observed that, all the motility characteristics of spermatozoa were significantly influenced by freezing and thawing, which reiterates earlier findings in Boer cross and Barbari goats (Sundararaman and Edwin, 2005). All the sperm motility and velocity parameters were significantly reduced in the post-thawing semen. Changes in the osmotic pressure during semen cryopreservation and thawing critically affect the motility and survival of the spermatozoa. This may be the most important deterrent to sperm survival during cryopreservation (Jamadiet al., 2017).

Furthermore, membrane destabilization might occur when the sperm plasma membrane undergoes a phase transition from the liquid crystalline phase to the gel phase due to a decrease in temperature during cryopreservation (Sundararaman and Edwin, 2008). 
Table.1

\begin{tabular}{|c|c|c|c|c|c|c|c|c|}
\hline \multicolumn{9}{|c|}{$\begin{array}{c}\text { Effect of TRIS semen extenders on sperm kinematic characteristics evaluated by CASA of post freeze stage buck semen at different storage } \\
\text { period }\end{array}$} \\
\hline $\begin{array}{c}\text { Duration of } \\
\text { storage period }\end{array}$ & $\begin{array}{c}\text { Sperm } \\
\text { motility }(\%)\end{array}$ & $\begin{array}{c}\text { Progressive } \\
\text { motility } \\
(\%)\end{array}$ & $\begin{array}{c}\text { Average path } \\
\text { velocity } \\
(\mu \mathrm{m} / \mathrm{s})\end{array}$ & $\begin{array}{c}\text { Straight } \\
\text { line velocity } \\
(\mu \mathrm{m} / \mathrm{s})\end{array}$ & $\begin{array}{c}\text { Curvilinear } \\
\text { velocity } \\
(\mu \mathrm{m} / \mathrm{s})\end{array}$ & $\begin{array}{c}\text { Amplitude of } \\
\text { lateral head } \\
\text { displacement }(\mu \mathrm{m})\end{array}$ & $\begin{array}{c}\text { Beat cross } \\
\text { frequency } \\
(\mathbf{H z})\end{array}$ & $\begin{array}{c}\text { Linearity } \\
\text { index } \\
(\%)\end{array}$ \\
\hline 24 hrs & $59.83 \pm 1.38$ & $39.19 \pm 1.50$ & $70.15 \pm 3.98$ & $58.61 \pm 3.89$ & $145.65 \pm 5.98$ & $6.9 \pm 0.5$ & $21.83 \pm 0.05$ & $40.89 \pm 0.30$ \\
\hline 48 hrs & $57.31 \pm 1.68$ & $35.69 \pm 1.50$ & $67.45 \pm 4.08$ & $55.61 \pm 3.19$ & $139.55 \pm 5.38$ & $6.6 \pm 0.5$ & $21.03 \pm 0.05$ & $39.56 \pm 0.5$ \\
\hline $10^{\text {th }}$ day & $55.61 \pm 1.38$ & $33.69 \pm 1.20$ & $65.15 \pm 4.01$ & $52.31 \pm 3.09$ & $135.15 \pm 5.04$ & $6.5 \pm 0.5$ & $20.83 \pm 0.05$ & $38.56 \pm 0.10$ \\
\hline $20^{\text {th }}$ day & $53.21 \pm 1.08$ & $30.69 \pm 1.01$ & $63.10 \pm 4.11$ & $51.30 \pm 4.39$ & $133.05 \pm 4.94$ & $6.3 \pm 0.5$ & $20.13 \pm 0.05$ & $38.36 \pm 0.10$ \\
\hline $3^{\text {th }}$ day & $51.21 \pm 1.51$ & $29.89 \pm 1.00$ & $62.10 \pm 4.11$ & $47.80 \pm 4.39$ & $125.05 \pm 4.14$ & $6.1 \pm 0.5$ & $19.13 \pm 0.05$ & $37.26 \pm 0.10$ \\
\hline
\end{tabular}

(Statistically all kinematic parameters (rows) differ significantly between different storage periods (columns))

Computer Assisted Semen Analyzer (CASA)

\begin{tabular}{|c|l|c|}
\hline No & \multicolumn{1}{|c|}{ Variables } & Settings \\
\hline 1 & Frame rate(Hz) & 60.00 \\
\hline 2 & Frames acquired & 30.00 \\
\hline 3 & Minimum contrast & 50.00 \\
\hline 4 & Minimum cell size & 5.00 \\
\hline 5 & Threshold straightness & 70.00 \\
\hline 6 & Medium VAP cut -off & 25.00 \\
\hline 7 & Low VAP cut-off & 5.00 \\
\hline 8 & Low VSL cut-off & 5.00 \\
\hline 9 & Non-motile head intensity & 70.00 \\
\hline 10 & Static size limit-minimum & 0.52 \\
\hline 11 & Static size limit-maximum & 1.99 \\
\hline 12 & Static intensity limit-minimum & 0.50 \\
\hline 13 & Static intensity limit-maximum & 1.25 \\
\hline 14 & Static elongation limit-minimum & 17.00 \\
\hline 15 & Static elongation limit-minimum & 66.00 \\
\hline \multicolumn{3}{|c|}{ Optic calibration } \\
\hline 16 & Magnification & 1.89 \\
\hline 17 & Camera frequency(Hz) \\
\hline
\end{tabular}


The irreversible changes in the sperm membrane induced by lipid phase transitions during cooling warming may possibly affect the movement characteristics of spermatozoa during semen processing for cryopreservation (Deleeuw et al., 1990). In addition, frozenthawed sperm are more vulnerable to oxidative stress due to peroxidation than sperm in freshly diluted semen (Neild et al., 2005). As semen is diluted many fold in the extender it reduces the total antioxidant concentration in the medium and cells (Kumar and Das, 2005). Many sperm are killed during cryopreservation. Thus, it is likely that cryopreserved sperm cells are posed to more ROS concentration and therefore many of the surviving cells postthaw exhibit as if they are capacitated or acrosome reacted (Bailey et al., 2000). The overall effects of these events may adversely affect quality of post thawing semen.

A total of 10 Tellicherry does were selected and all the does were inseminated with frozen thawed buck semen prepared from TRIS universal diluent and the pregnancy was confirmed by ultrasonography at 45 days of gestation.

Out of 10 does 7 does were conceived ( 70 per cent) and the remaining does were conceived during subsequent estrus.

The effect of TRIS semen extenders on sperm kinematic characters evaluated by CASA of post freeze stage of Boer crossbred buck semen at different storage period decrease progressively as the duration storage period increases. The fertility rate was good using this frozen thawed Boer crossbred buck semen (70 per cent). TRIS extender augment fertility in does more than 50 per cent and hence, TRIS can be used as universal extender for cryopreservation with less cryo damage with maximum conception rate for Boer crossbred buck semen.

\section{References}

Amle, M.B., H.S Birade and S.U. Gulawane, 2017. Estrus Response and Conception Rate in Sangamneri and Osmanabadi Goat Does using different Estrus Synchronization Protocols. International Journal of Advanced Veterinary Science and Technology. 6: 308-315.

Bailey, J.L., J.F. Bilaodean and N. Cormie, 2000. Semen cryopreservation in domestic animals: A damaging capacitating phenomenon. J. Androl.,20: 1-7.

Baldassarre, H., and C. N. Karatzas, 2004. Advanced assisted reproduction technologies (ART) in goats. Anim Reprod Sci.82-83: 255-66.

De leeuw, F.E., H.C. Chen, B. Colenbrander and A.J. Verkleij, 1990. Cold-induced ultrastructural changes in bull and boar sperm plasma membranes. Cryobiology, 27: 171-183.

Jamadi, A.S., E. Ahmad, M. Ansari and H.Kohram, 2017.Antioxidant effect of quercetin in an extender containing DMA or glycerol on freezing capacity of goat semen. Cryobiology. 75:15-20.

Kumar, S., and G. K. Das, 2005. Frozen sperm quality with reference to reactive oxygen species: A review. Indian. J. Anim. Sci., 75: 874-884.

Moussa, M., V.Martinet, A.Trimeche, D. Tainturier and M. Anton, 2002. Low density lipoproteins extracted from hen egg yolk by an easy method: cryoprotective effect on frozen-thawed bull semen. Theriogenology,57: 16951706.

Neild, D.M., J.P. Brouwers, B. Colenbrander, A. Aguero and B.M. Gadella, 2005. Lipid peroxide formation in relation to membrane stability of fresh and frozen-thawed stallion spermatozoa. Mol. Reprod. Dev.,72: 230-238. 
Ramsay, K.A., C.H Smit and N.H. Casey 1987. The potential of the indigenous veld goat as an alternative to the impreoved Boer goat of south Africa.Proc. $4^{\text {th }}$ Int.Con.onGoats, $\mathrm{VolII}, \mathrm{Br}$ azil.

Singh, N. S., P. G. Gawande, O. P Mishra, R. K. Nema, U. K. Mishra and Mohan Singh, 2004. Accuracy of Ultrasonography in Early Pregnancy Diagnosis in Doe. J. Anim. Sci., 17: 760768.

Sundararaman, M. N., J. Kalatharan and K. Thilak Pon Jawahar, 2012. Computer assisted semen analysis for quantification of motion characteristics of bull sperm during cryopreservation cycle. Vet. World.,5: 723-726.

Sundararaman, M.N., and M.J. Edwin, 2005. Evaluation of sperm motion characteristics of pre-freeze and postthaw goat spermatozoa on Computer Assisted Semen Analysis (CASA). Indian. J. Small. Rumin., 11: 92-95.

Sundararaman, M.N., and M.J. Edwin, 2008. Changes in Motility Characteristics of Goat Spermatozoa during GlycerolEquilibration and the Relevance to Cryopreservation. Asian Journal of Cell Biology, 3: 22-33.

\section{How to cite this article:}

Manivannan, S., M. Selvaraju, R. Ezakial Napolean and Sesh, P.S.L. 2017. Post-Thaw Evaluation of Cryopreserved Boer Crossbred Buck Semen Extended in TEYG (Universal) Extender and its Fertility Rate. Int.J.Curr.Microbiol.App.Sci. 6(9): 3044-3049. doi: https://doi.org/10.20546/ijcmas.2017.609.374 